\title{
Antibacterial Activities of the Methanolic Extract of Bangladeshi Black Tea against Various Human Pathogens
}

\author{
Mohammad Shahnoor Hossain, Yead Morshed Nibir, Sayma Zerin \\ and Nazmul Ahsan
}

\author{
Department of Genetic Engineering \& Biotechnology, University of Dhaka, Dhaka-1000, Bangladesh
}

Received: March 25, 2014; Accepted: April 28, 2014; Published (web): June 29, 2014

\begin{abstract}
The goal of the present study was to evaluate the antibacterial activity of the methanolic extract of Bangladeshi black tea against various important pathogenic bacteria. Antibacterial activity test was carried out by agar well-diffusion method. Minimum inhibitory concentration (MIC) and minimum bactericidal concentration (MBC) were evaluated using microdilution methods. Extract of Bangladeshi black tea demonstrated potential antibacterial activity in a dose dependent manner against all of the tested bacteria and exhibited highest activity against two common enteric pathogens, Shigella boydii and Vibrio cholerae with MIC and MBC of $200 \mu \mathrm{g} / \mathrm{ml}$ and 1 $\mathrm{mg} / \mathrm{ml}$ respectively. Our results indicate that black tea extract can be used as therapeutic to control these deadly pathogens.
\end{abstract}

Key words: Antibacterial, pathogenic bacteria, MIC, MBC, black tea

\section{INTRODUCTION}

Even after 70 years of antibiotic invention, infectious disease still remains a serious public health concern. This situation has been further deteriorated by the ever-increasing trends of antibiotic resistance among pathogenic bacteria. This has given the new impulse to scientific community to turn their focus on herbal or natural products to fight this escalating problem. Since the herbal products contain various components with numerous biological activities, they are being used all over the world as a remedy for various diseases. ${ }^{1-3}$ Tea, well known as a panacea for numerous diseases, holds a great promise to be used as an anti-infective agent to control various pathogenic bacteria. ${ }^{4-6}$ Numerous studies have revealed that tea is associated with various physiological and pharmacological benefits including antidiabetic, anti-inflamatory, antioxidant, anticholesterolemic, antimutagenic and anticarcinogenic activities in addition to its antimicrobial properties. ${ }^{7-10}$

Correspondence to: Mohammad Shahnoor Hossain

Phone: 8802-9661920/7824 (off.); 8801554593702

Fax: 88028615583

E-mail: mshahnoor@du.ac.bd

Dhaka Univ. J. Pharm. Sci. 13(1): 97-103, 2014 (June)
Tea, the most commonly used beverage in the world, is an aqueous infusion of the processed leaves of Camellia sinensis. ${ }^{11}$ Three different types of tea are generally available all over the world, such as black tea (fermented), green tea (non-fermented), and oolong tea (semi-fermented). ${ }^{10}$

Tea contains a lot of polyphenols (known as catechins and their derivatives) which are responsible for numerous biological activities. ${ }^{5,12,13}$ Distinct types of polyphenolic components are present in black tea due to extra-oxidation during fermentation process. ${ }^{7}$ Whereas green tea contains mainly flavanols or catechins of epigallocatechin gallate (EGCG), epigallocatechin (EGC), epicatechin gallate (ECG), and epicatechin (EC); black tea is improved with complex flavonoides called theaflavins and thearubigins. $^{7,9,14,15}$ Moreover, quality and composition of the tea differs based on regional and environmental factors, such as Assamese tea (Camellia sinensis var. assamica), predominantly produced in South Asia, and contains much more polyphenol than oriental tea. ${ }^{10}$ Several previous studies have reported the antimicrobial activities of green and oolong tea, however, relatively little is known about the antimicrobial activities of black tea. ${ }^{6,7,13,16-22}$ The aim of the present study was to 
assess the antibacterial activities of the methanolic extract of Bangladeshi black tea, known as flowery broken orange pekoe (FBOP) against a range of pathogenic bacteria.

\section{MATERIALS AND METHODS}

Bacterial strains and culture. Bacterial strains were obtained from the Department of Genetic Engineering and Biotechnology, University of Dhaka. Vibrio cholerae, Shigella dysenteriae, Shigella boydii, Salmonella typhi, Salmonella paratyphi, Enterobacter aerogenes, Klebsiella pneumoniae, Escherichia coli, and Pseudomonas aeruginosa were regularly grown in either nutrient agar or broth medium (HiMedia, India) at $37^{\circ} \mathrm{C}$ with shaking. Bacillus cereus, Staphylococcus aureus, MRSA (Methicillin-resistant Staphylococcus aureus), Enterococcus faecalis were cultivated in trypticase soy medium (HiMedia, India) at $37^{\circ} \mathrm{C}$ except Listeria monocytogenes which was incubated at $30^{\circ} \mathrm{C}$. Streptococcus spp. was cultivated in brain heart infusion medium (Scharlau.co, EU), when necessary supplemented with $5 \%$ sheep blood at $37^{\circ} \mathrm{C}$ in microaerophilic condition.

Preparation of methanolic extract of Bangladeshi black tea. Black tea, (FBOP) collected $(50 \mathrm{~g})$ from the local market as granular powder was soaked in $200 \mathrm{ml}$ methanol (Sigma, USA) in a flask. The flask was covered and then kept at room temperature for $8 \mathrm{~h}$. After that the solution was filtered with Whatman filter (No. 11) in order to eliminate all granular materials. Filtered tea extract was then subjected to rotary evaporation to remove methanol, followed by freeze drying to get the dried powder. Yield of the extract was $\sim 15 \%$. Dried extract was stored at $4{ }^{\circ} \mathrm{C}$ and when necessary it was dissolved in phosphate buffer saline (PBS) as 200 $\mathrm{mg} / \mathrm{ml}$ working solution.

Antimicrobial sensitivity assay. Agar well diffusion method was used to measure the antimicrobial sensitivity using Mueller Hinton agar medium (Difco, USA). Tea extract was tested against various bacteria at different concentrations $(50,100$ and $200 \mathrm{mg} / \mathrm{ml})$. Kanamycin solution $(10 \mathrm{mg} / \mathrm{ml})$ and
PBS (0.1M) was used as positive and negative control, respectively. Overnight grown bacteria was first adjusted to 0.5 McFarland turbidity standards $\left(\sim 1.0 \times 10^{8} \mathrm{cfu} / \mathrm{ml}\right)$ and seeded onto Mueller Hinton agar with a sterile cotton swab. Plates were then left at room temperature for $15 \mathrm{~min}$ and wells were made using a sterile borer. The test extracts or control (PBS and kanamycin) were then added into the well $(20 \mu \mathrm{l}$ to each well) and incubated for overnight. The activity was determined by measuring the diameter of the zone of inhibition in millimeter $(\mathrm{mm})$ using a scale. Three independent experiments were performed in triplicate for each bacterium.

Determination of minimum inhibitory concentration (MIC) and minimum bactericidal concentration (MBC). To determine the MIC and MBC of the methanolic extract of the black tea, a stock solution of $8 \mathrm{mg} / \mathrm{ml}$ and another stock solution of $6.4 \mathrm{mg} / \mathrm{ml}$ were prepared in PBS. As per the guidelines of Clinical and Laboratory Standards Institute, the broth microdilution method with minor modification was used to assess the MIC and $\mathrm{MBC}^{23,24}$. Briefly, overnight grown stationary phase bacterial culture was adjusted to 0.5 McFarland standards $\left(\sim 1.0 \times 10^{8} \mathrm{cfu} / \mathrm{ml}\right)$ and inoculated into Mueller Hinton broth with serially diluted tea extract in 96-well round-bottomed micro-titer plates. After $18 \mathrm{~h}$ of incubation, $10 \mu \mathrm{l}$ of serially diluted cultures were plated onto tryptic soy agar as drop plate method and incubated for $24 \mathrm{~h}$ to $48 \mathrm{~h}$. MIC was measured as the minimum concentration of tea extract which caused visible growth inhibition on agar plate. The MBC was determined as the lowest concentration of extract which produced $99.9 \%$ reduction of the number of CFU onto agar plates in compare with control.

Effects of incubation time on bacterial killing. To investigate the effects of incubation time on bactericidal activity, tea extract at MBC concentrations were added into 1:100 dilution of overnight grown bacteria in PBS and incubated for different time periods at $37^{\circ} \mathrm{C}$. A control was also incubated without addition of any tea extract. After incubation, the bacteria were serially diluted into 
PBS and plated onto tryptic soy agar in triplicate and incubated at $37^{\circ} \mathrm{C}$ for viable counts and measured as colony forming units (CFU). Agar plate containing less than $300 \mathrm{CFU}$ was considered for assessment. PBS was used as control. The size of the inoculums was determined by separate plating of serially diluted inoculums, followed by viable counts.

\section{RESULTS}

Antibacterial activity of the black tea extract. In this study, we investigated whether methanolic extract of Bangladeshi black tea could significantly inhibit the growth and activity of various common human pathogens. The antibacterial activity was evaluated at the concentrations of 50, 100 and 200 $\mathrm{mg} / \mathrm{ml}$ by agar well diffusion method (Fig. 1). The average zones of bacterial growth inhibition are shown in Table 1. The results revealed that all of the tested bacteria are sensitive to black tea extract. The maximum inhibitory activity was found against $S$. boydii, which produced $31 \mathrm{~mm}$ diameter of inhibition zone at $200 \mathrm{mg} / \mathrm{ml}$ concentration. On the other hand, E. coli was less sensitive as they displayed small zone of inhibition as compared to other bacteria. Our results also indicated that Gram negative bacteria are much more sensitive to tea extract in compare to Gram positive bacteria. However, among the Gram positive bacteria $S$. aureus (MRSA) exhibited highest susceptibility.

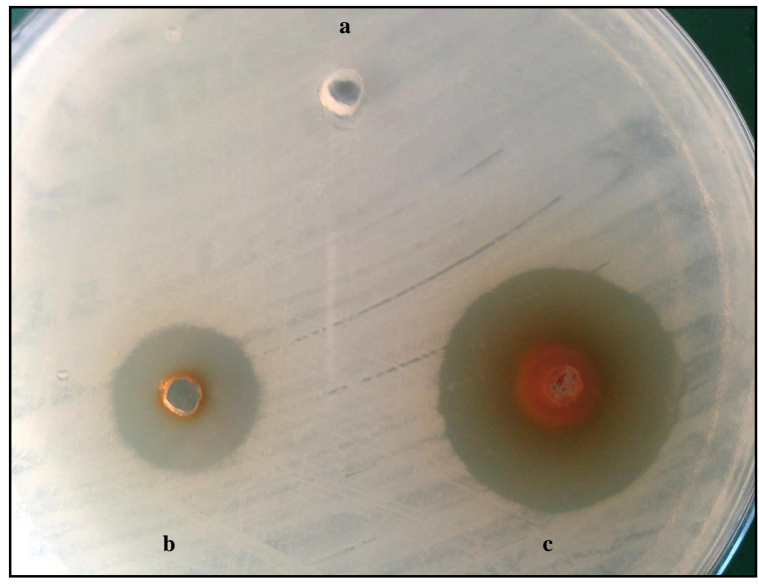

Figure 1. Inhibitory activities of black tea extract on various pathogenic bacteria. Overnight grown bacterial cultures were first adjusted to $0.5 \mathrm{McFarland}$ turbidity standards $\left(\sim 1.0 \times 10^{8}\right.$ $\mathrm{cfu} / \mathrm{ml}$ ) and swabbed onto Mueller Hinton agar with a sterile cotton swab and wells were made using a sterile borer. The test extracts or control (PBS) were then added into the wells at (a) PBS control; (b) $50 \mathrm{mg} / \mathrm{ml}$ and (c) $100 \mathrm{mg} / \mathrm{ml}$ concentrations and incubated for $24 \mathrm{~h}$. The zones of inhibition around the wells were observed and measured as millimeter $(\mathrm{mm})$ in diameter. These plates are representative of at least three independent experiments.

Table 1. Zones of bacterial growth inhibition by the methanolic extract of Bangladeshi black tea.

\begin{tabular}{lcccc}
\hline \multicolumn{1}{c}{ Bacteria } & \multicolumn{3}{c}{ Zone of inhibitions $(\mathrm{mm})$} \\
\cline { 2 - 4 } & $50 \mathrm{mg} / \mathrm{ml}$ & $100 \mathrm{mg} / \mathrm{ml}$ & $200 \mathrm{mg} / \mathrm{ml}$ & Kanamycin $(10 \mathrm{mg} / \mathrm{ml})$ \\
\hline S. aureus & $14.0 \pm 1.0$ & $18.0 \pm 1.0$ & $22.0 \pm 1.0$ & $35 \pm 1.5$ \\
S. aureus MRSA & $15.0 \pm 1.0$ & $19.0 \pm 1.0$ & $21.0 \pm 1.0$ & $36 \pm 1.5$ \\
S. epidermidis & $12.0 \pm 1.0$ & $16.0 \pm 1.0$ & $20.0 \pm 1.0$ & $33 \pm 1.0$ \\
S. mutans & $9.0 \pm 1.0$ & $12.0 \pm 1.0$ & $14.0 \pm 1.0$ & $29 \pm 1.0$ \\
S. pyogenes & $11.0 \pm 0.5$ & $13.0 \pm 0.5$ & $16.0 \pm 0.5$ & $28 \pm 1.0$ \\
B. cereus & $10.0 \pm 0.5$ & $12.0 \pm 0.5$ & $15.0 \pm 1.0$ & $32 \pm 1.0$ \\
P. aeruginosa & $12.0 \pm 1.0$ & $15.0 \pm 1.0$ & $18.0 \pm 0.5$ & $25 \pm 1.0$ \\
V. cholerae & $17.0 \pm 1.0$ & $23.0 \pm 1.0$ & $29.0 \pm 1.5$ & $30 \pm 1.0$ \\
E. coli & $9.0 \pm 1.0$ & $12.0 \pm 1.0$ & $14.0 \pm 1.0$ & $36 \pm 1.0$ \\
K. pneumoniae & $11.0 \pm 1.0$ & $15.0 \pm 1.0$ & $20.0 \pm 2.0$ & $35 \pm 1.0$ \\
E. aerogenes & $15.0 \pm 1.0$ & $23.0 \pm 1.0$ & $28.0 \pm 2.0$ & $37 \pm 1.0$ \\
S. dysenteriae & $14.0 \pm 1.0$ & $21.0 \pm 1.0$ & $27.0 \pm 2.0$ & $36 \pm 1.0$ \\
S. boydii & $17.0 \pm 1.0$ & $25.0 \pm 2.0$ & $31.0 \pm 2.0$ & $30 \pm 1.0$ \\
S. typhimurium & $13.0 \pm 1.0$ & $19.0 \pm 1.0$ & $25.0 \pm 2.0$ & $36 \pm 1.0$ \\
S. paratyphi & $12.0 \pm 1.0$ & $19.0 \pm 1.0$ & $22.0 \pm 2.0$ & $35 \pm 1.0$ \\
E. faecalis & $8.0 \pm 1.0$ & $12.0 \pm 1.0$ & $14.0 \pm 1.0$ & $26 \pm 1.0$ \\
L. monocytogenes & $10.0 \pm 1.0$ & $15.0 \pm 1.0$ & $19.0 \pm 1.0$ & $29 \pm 1.0$ \\
\hline V.
\end{tabular}

Values are means \pm standard deviations resulting from at least three independent experiments performed in duplicates. CI, denotes the clinical isolates which were isolated and identified from clinical specimens (to be published elsewhere). 
Determination of MICs and MBCs. The minimum inhibitory concentration (MIC) and the minimum bactericidal concentrations (MBC) of the black tea extract against the tested bacteria are shown in Table 2. In an agreement with our qualitative assay, obtained MIC and MBC values also indicated that Gram negative bacteria were comparatively more susceptible to tea extract than Gram positive bacteria. S. boydii remains to be more susceptible to black tea extract than other Gram negative bacteria. The MIC and MBC values for $S$. boydii were $200 \mu \mathrm{g} / \mathrm{ml}$ and $1.0 \mathrm{mg} / \mathrm{ml}$, respectively. On the other hand, group A streptococcus ( $S$. pyogenes) and cariogenic bacteria $S$. mutans were less susceptible to black tea extract and the MIC and MBC values were $1.6 \mathrm{mg} / \mathrm{ml}$ and $3.2 \mathrm{mg} / \mathrm{ml}$, respectively (Table 2).
Table 2. Minimum inhibitory concentrations (MICs) and minimum bactericidal concentrations (MBCs) of the Bangladeshi black tea against various pathogenic bacteria.

\begin{tabular}{lcc}
\hline Bacteria & $\begin{array}{c}\mathrm{MIC} \\
(\mu \mathrm{g} / \mathrm{ml})\end{array}$ & $\begin{array}{c}\mathrm{MBC} \\
(\mathrm{mg} / \mathrm{ml})\end{array}$ \\
\hline S. aureus & 400 & 1.6 \\
S. aureus MRSA & 400 & 1.6 \\
S. epidermidis & 250 & 1.6 \\
S. mutans GS5 & 800 & 3.2 \\
S. pyogenes & 800 & 3.2 \\
B. cereus & 500 & 2.0 \\
P. aeruginosa & 400 & 2.0 \\
V. cholerae & 200 & 1.0 \\
E. coli & 800 & 2.0 \\
K. pneumoniae & 500 & 1.6 \\
E. aerogenes & 250 & 1.6 \\
S. dysenteriae & 200 & 1.0 \\
S. boydii & 200 & 1.0 \\
S. typhimurium & 250 & 1.6 \\
S. paratyphi & 250 & 1.6 \\
E. faecalis & 400 & 3.2 \\
L. monocytogenes & 400 & 3.2 \\
\hline
\end{tabular}

The results presented here are representative of at least three independent experiments performed in duplicates.

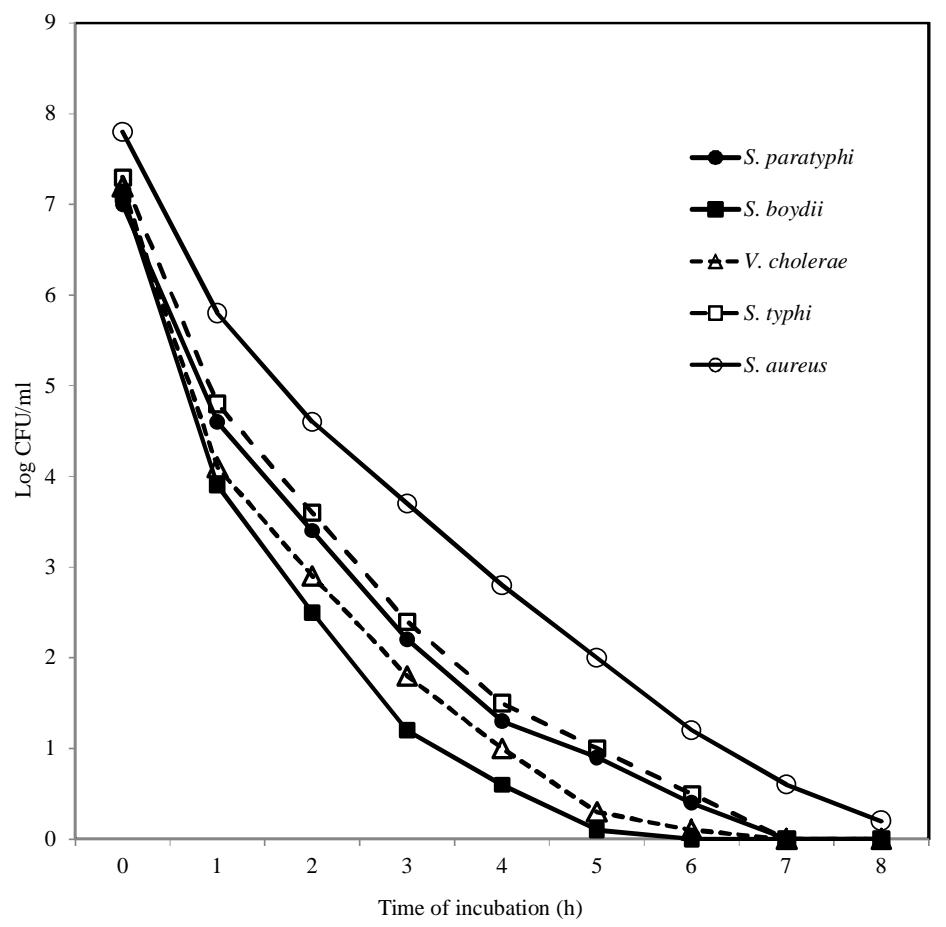

Figure 2. Time requirements for bacterial survival at $\mathrm{MBC}$ of black tea extract. Bacterial cultures were grown for overnight at $37^{\circ} \mathrm{C}$ and diluted (1:100) into sterile PBS solution ( $\mathrm{pH}$ 7.4), followed by addition of black tea extract at MBC concentrations as mentioned in Table-2 and incubation at $37^{\circ} \mathrm{C}$. Bacterial cultures were taken out at different time intervals and plated onto tryptic soy agar medium after serial dilution into PBS. After $24 \mathrm{~h}$ incubation at $37^{\circ} \mathrm{C}$, the viable counts were recorded as colony forming unit (CFU). The

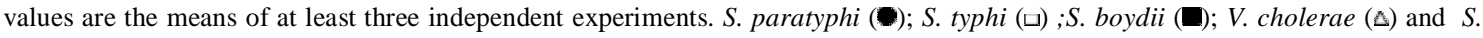
aureus (o). 


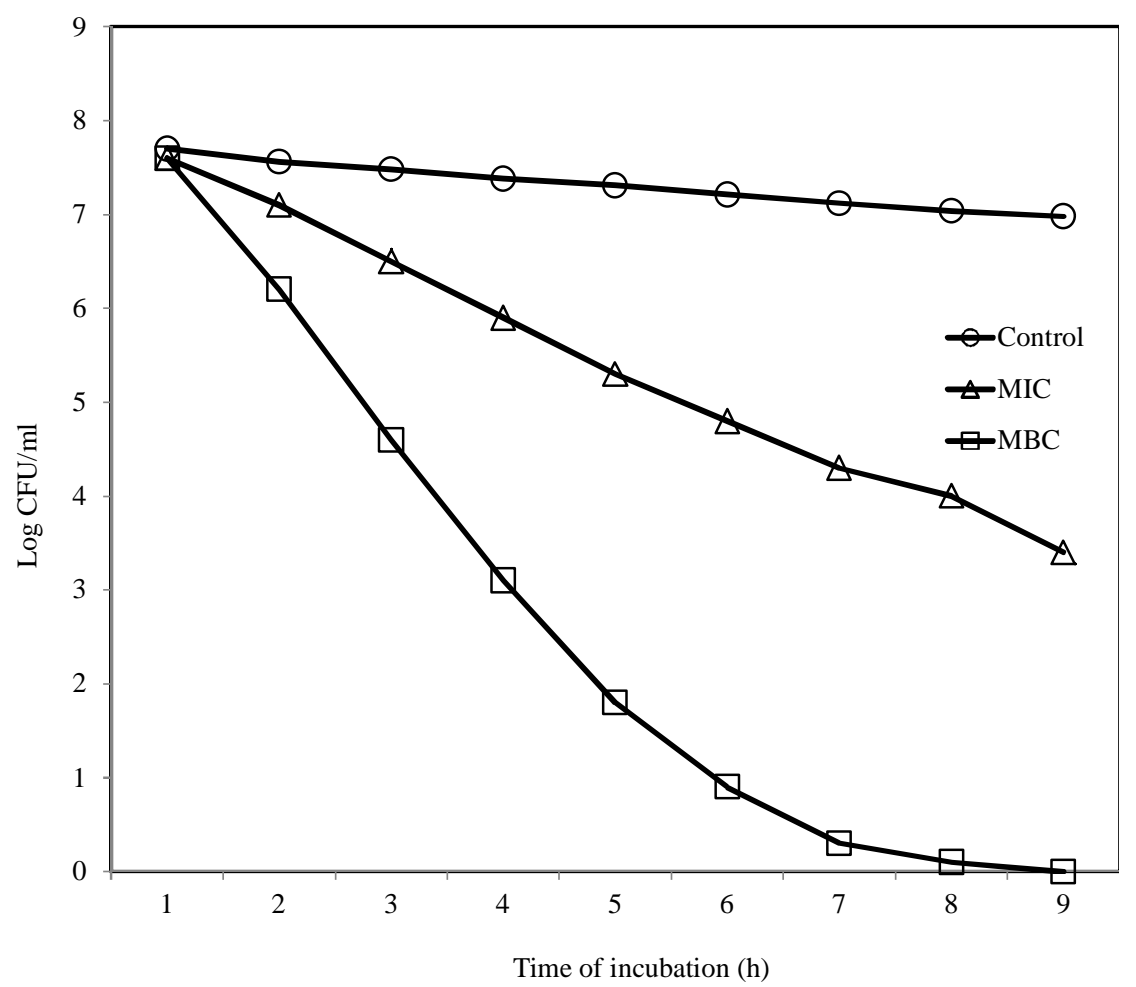

Figure 3. Relationship between period of exposure and different concentration on the survival of S. boydii. S. boydii cultures were grown for overnight at $37^{\circ} \mathrm{C}$ and diluted (1:100) into sterile phosphate-buffered saline solution (pH 7.4), followed by addition of black tea extract at $182 \mu \mathrm{g} / \mathrm{ml}$ and $1000 \mu \mathrm{g} / \mathrm{ml}$ concentrations and incubation at $37^{\circ} \mathrm{C}$. Bacterial cultures were taken out at different time intervals and plated onto tryptic soy agar medium after serial dilution into PBS. After $24 \mathrm{~h}$ incubation at $37^{\circ} \mathrm{C}$, viable counts were recorded as colony forming unit (CFU). The values are the means of at least three independent experiments performed in duplicates. Control (o); MIC ( $\triangle$ ) and MBC (ㅁ).

\section{Effects of the duration of incubation time on} bacterial growth at MBCs. To investigate the effects of incubation time on bacterial growth inhibition, the overnight grown bacterial culture was incubated in PBS buffer at 1:100 dilution along with the extract at MBC concentrations and determined the viable counts at different time interval. It was found that the death of bacteria cells was dependent on the duration of incubation (Fig. 2 and Fig. 3). However, the incubation time for cell death was prolonged when it was incubated at lower concentration (Fig. 3). In presence of tea extract, we observed a significant negative correlation between viable counts (CFU) and the times of incubation. Incubation of bacterial cells for $1 \mathrm{~h}$ with tea extract at their MBC concentrations caused about one-tenth reduction of $\mathrm{CFU}$ value for most cases. Eight hours of incubation with black tea extract was sufficient to abolish the viable count in case of most of the tested bacteria. Nonetheless, the required time for bacterial killing varied from species to species. Longer time was needed to kill L. monocytogenes, E. coli, $S$. pyogenes, and $S$. mutans than $S$. boydii, S. typhi, $V$. cholera, E. aerogenes and MRSA. About $15 \mathrm{~h}$ was required to kill $E$. coli and $S$. pyogenes, whereas 7-8 h was sufficient to kill $S$. boydii, S. typhi, $S$. paratyphi, $V$. cholera, Enterobacter and MRSA (Figure 2 and data not shown).

\section{DISCUSSION}

Tea is one of the most popular beverages in the world and black tea accounts more than three-fourth of the world tea production. ${ }^{25}$ In this study, we reported that methanolic extract of Bangladeshi black tea showed significant antibacterial activities against a range of pathogenic bacteria. Our results demonstrated that only one hour of incubation with black tea extract caused drastic reduction in bacterial 
cell number. However, the extent of the inhibitory effects differed based on bacterial strains. In an agreement with some previous reports on green tea, our results also indicated that Bangladeshi black tea extract could inhibit the enteric bacteria prominently. ${ }^{6}$ Among the enteric pathogens, $S$. boydii, S. dysenteriae, S. paratyphi, S. typhimurium, $V$. cholerae, K. pneumoniae and E. aerogenes were highly susceptible to black tea extract. $S$. boydii shown to be most susceptible whereas E. coli remains less susceptible. $P$. aeruginosa was also significantly inhibited as like other Gram negative bacteria. Among the Gram positive bacteria, $S$. aureus and $S$. epidermidis were found much more sensitive than oral streptococci and the food-borne pathogen, B. cereus. Regarding the inhibitory spectrum, our results are in accordance with several previous studies based on green tea. ${ }^{19,26}$ In contrast with a previous report, our results further demonstrated that $S$. typhimurium is susceptible to tea extract. ${ }^{27}$

\section{CONCLUSION}

In this study, we systematically tested the methanolic extract of Bangladeshi black tea against a range of human pathogens and demonstrated that black tea extract showed noticeable inhibitory activity against almost all of the tested bacteria. Antibacterial activities against the common enteric pathogens suggested that black tea extract can be effectively used with oral rehydration therapy to treat the patients with gastrointestinal infections. Therefore, further studies with purified components and the clinical trials to assess the safety and efficacy of tea extract are essential prior to use this as therapeutic agent.

\section{ACKNOWLEDGEMENTS}

We thank Biotechnology Research Center, University of Dhaka for providing the partial grant to continue this project. Authors are also thankful to Center for Advanced Research in Sciences, University of Dhaka for freeze drying.

\section{REFERENCES}

1. Calixto, J.B. 2005. Twenty-five years of research on medicinal plants in Latin America: a personal view. $J$. Ethnopharmacol. 100, 131-134.

2. Melendez, P.A. and Capriles, V. A. 2006. Antibacterial properties of tropical plants from Puerto Rico. Phytomed. Int. J. Phyther.\& Phytopharmacol. 13, 272-276.

3. de Oliveira, J.F., de Castro, V.C., Vilela, P.G.F., Camargo, S.E.A., Carvalho, C.A.T., Antonio Olavo Cardoso Jorge, A.O.C. and de Oliveira, L.D. 2013. Cytotoxicity of Brazilian plant extracts against oral microorganisms of interest to dentistry. BMC compl. Alt. Med. 13, 208.

4. Ferrazzano, G.F., Roberto, L., Amato, I., Cantile,T., Sangianantoni, G. and Ingenito, A. 2011. Antimicrobial properties of green tea extract against cariogenic microflora: an in vivo study. J. Med. Food. 14, 907-911.

5. Shimamura, T., Zhao, W.H. and Hu, Z.Q. 2007. Mechanism of Action and Potential for Use of Tea Catechin as an Antiinfective Agent. Anti-Infect. Agents Med. Chem. 6, 5762.

6. Ahn, Y.J., Sakanaka, S., Kim, M.J., Kawamura, T., Fujisawa,T. and Mitsuoka, T. 1990. Effects of green tea extracts on growth of intestinal bacteria. Microb. Ecol. Health Dis. 3, 335-338.

7. Hamilton-Miller, J.M. 1995. Antimicrobial properties of tea (Camellia sinensis L.). Antimicrob. Agents \& Chemother. 39, 2375-2377.

8. Xu, X., Zhou, X.D. and Wu, C.D. 2011. The tea catechin epigallocatechin gallate suppresses cariogenic virulence factors of Streptococcus mutans. Antimicrob. Agents \& chemother. 55, 1229-1236.

9. Beresniak, A., Duru, G., Berger, G. and Bremond-Gignac, D. 2012. Relationships between black tea consumption and key health indicators in the world: an ecological study. BMJ Open. 2, 648.

10. Cabrera, C., Artacho, R. and Gimenez, R. 2006. Beneficial effects of green tea--a review. J. Ame. Coll. Nutri. 25, 79-99.

11. Graham, H.N. 1992. Green tea composition, consumption, and polyphenol chemistry. Prev. Med. 21, 334-350.

12. Fraga, C.G., Martino, V.S., Ferraro, G.E., Coussio, J.D. and Boveris, A. 1987. Flavonoids as antioxidants evaluated by in vitro and in situ liver chemiluminescence. Biochem. Pharmacol. 36, 717-720.

13. Yamamoto, T. 1997. Chemistry and application of green tea. CRC Press, Inc., Boca Raton. Fla. 51-52.

14. Menet, M.C., Sang, S., Yang, C.S., Ho, C.T. and Rosen, R.T. 2004. Analysis of theaflavins and thearubigins from black tea extract by MALDI-TOF mass spectrometry. $J$. Agric. Food. Chem. 52, 2455-2461.

15. Lee, K.W., Lee, H.J. and Lee, C.Y. 2002. Antioxidant activity of black tea vs. green tea. J. Nutri. 132, 785-786. 
16. Sasaki, H., Matsumoto, M., Tanaka, T., Maeda, M., Nakai, M., Hamada, S. and Ooshima, T. 2004. Antibacterial activity of polyphenol components in oolong tea extract against Streptococcus mutans. Caries Res. 38, 2-8.

17. Naderi, N.J., Niakan, M., Kharazi Fard, M.J. and Zardi, S. 2011. Antibacterial activity of Iranian green and black tea on streptococcus mutans: an in vitro study. J. Dent. (Tehran). 8, 55-59.

18. Toda, M., Okubo, S., Hara, Y. and Shimamura, T. 1991. Antibacterial and bactericidal activities of tea extracts and catechins against methicillin resistant Staphylococcus aureus. Nihon Saikingaku Zasshi. 46, 839-845.

19. Toda, M., Okubo, S., Ohnishi, R. and Shimamura, T. 1989. Antibacterial and bactericidal activities of Japanese green tea. Nihon Saikingaku Zasshi. 44, 669-672.

20. Mabe, K., Yamada, M., Oguni, I. and Takahashi, T. 1999. In vitro and in vivo activities of tea catechins against Helicobacter pylori. Antimicrob. Agents Chemother. 43, 1788-1791.

21. Jankun, J., Selman, S.H., Swiercz, R. and SkrzypczakJankun, E. 1997. Why drinking green tea could prevent cancer. Nature. 387, 561.

22. Liang, O.D., Kleibrink, B.E., Schuette-Nuetgen, K., Khatwa, U.U., Mfarrej, B. and Subramaniam, M. 2011. Green tea epigallo-catechin-galleate ameliorates the development of obliterative airway disease. Exp. Lung Res. 37, 435-444.
23. Clinical and Laboratory Standards Institute. Methods for dilution antimicrobial susceptibility tests for bacteria that grow aerobically. 2009. 8th ed. vol. 29(2). Wayne, PA: CLSI.

24. European Committee for Antimicrobial Susceptibility Testing (EUCAST) of the European Society of Clinical Microbiology and Infectious Diseases (ESCMID), Determination of minimum inhibitory concentrations (MICs) of antibacterial agents by broth dilution. EUCAST discussion document E.dis. 5.1. 2003. Clinical Microbiol. Infect. 9, 1-7.

25. Chen, H., Hayek, S., Guzman, J.R., Gillitt, N.D., Ibrahim, S.A., Jobin, C. and Sang, S. 2012. The microbiota is essential for the generation of black tea theaflavins-derived metabolites. PLoS One. 7, e51001.

26. Toda, M., Okubo, S., Hiyoshi, R. and Shimamura, T. 1989. The bactericidal activity of tea and coffee. Lett. Appl. Microbiol. 8, 123-125.

27. Hara, Y. and Ishigami, T. 1989. Antibacterial activities of tea polyphenols against foodborne pathogenic bacteria. $J$. Jpn. Soc. Food Sci. Technol. 36, 996-999. 